\title{
Introducing new joint replacements to clinical practice
} Requires collaboration between clinicians and regulators, together with comprehensive surveillance data

\author{
John A Skinner consultant orthopaedic surgeon ${ }^{1}$, Peter R Kay consultant orthopaedic surgeon ${ }^{2}$, \\ Alister $\mathrm{J}$ Hart consultant orthopaedic surgeon ${ }^{3}$
}

${ }^{1}$ Royal National Orthopaedic Hospital, Stanmore HA7 4LP, UK; ${ }^{2}$ Wrightington Hospital, Wigan, UK; ${ }^{3}$ Imperial College, London, UK

Total hip arthroplasty is one of the greatest success stories in modern medicine. Since its inception in the late 1960s, millions have benefited from its ability to relieve pain and improve function, and it is now so successful that it is being used to treat arthritis of the hip in younger patients. The two problems with arthroplasty have always been fixation and wear. In the 1980s, the problem of fixation of components to the skeleton was overcome with both cemented and uncemented component designs that were developed to give excellent and long lasting fixation. Modifications of bearing surfaces and implant design have been introduced in an attempt to improve function, wear resistance, and implant survival. The recently published systematic review by Sedrakyan and colleagues used data from clinical trials, observational studies, and arthroplasty registries to compare traditional metal on polyethylene bearings with newer ceramic on ceramic and metal on metal bearings. ${ }^{1}$ The last two "hard on hard" bearings were thought to be advances that would reduce wear and facilitate hip resurfacing and the use of larger diameter femoral head sizes, which confer increased stability in arthroplasty. ${ }^{2}{ }^{3}$ The review shows that the perceived advantages are not being reflected in outcomes in arthroplasty registries. ${ }^{1}$ Some metal bearing hips have been associated with high complication rates.

All innovation carries risk, but without innovation patient care will not be improved. An efficient and timely process is needed to minimise the risks but also support the process of innovation, rather than restrict or delay it. Currently, there is a mismatch between the evidence from joint registries and the trends in joint replacement: cemented cups need to be revised least often in the first five years but their use is declining. This implies that surgeons see sources of data other than registers as important.

Joint registries allow the creation of large datasets in an area in which many small, albeit controlled, studies have been published. Controlled studies have limitations-for example, can all surgeons perform all implant types equally well? However, registries also have limitations, such as the quality and completeness of data entry. In addition, they tend to focus on failure (revision or redo surgery) as the only outcome measure, with little regard for function. ${ }^{4}$ The Birmingham hip resurfacing arthroplasty study has shown excellent results at 10 years in the most challenging patient group for arthroplasty surgeons-namely, active men under 55 years of age who have large hips and normal or impingement anatomy. ${ }^{5}$ However, this apparent advantage was not evident from the data captured by joint registries in the first five years, possibly because it is a technically difficult operation and many surgeons may be using the device for different indications with less certain results.

The introduction of new artificial hip implants is an important multidisciplinary field with close relationships between industry, non-clinical and clinical scientists, healthcare regulators, and surgeons. The systems to manage the introduction of new implants should ideally apply robust scientific evidence in a standardised manner that still encourages innovation. However, the higher rates of failure and unexpected mechanisms of failure seen with metal on metal hip implants have stimulated a review of the system of medical device regulation by the United States Food and Drug Administration. ${ }^{6}$ Of particular concern is the fast track route, whereby a device is claimed to have equivalent safety and efficacy to those devices already in use-the "me too group" approved by premarket notification under the $510(\mathrm{k})$ clearance. Small changes to prosthesis design often have big effects on clinical outcomes. ${ }^{7}$ In Europe, the CE (European conformity) marking system is also open to less rigorous scrutiny: approval by one of the many official CE awarding bodies enables pan-European use of a new device. There is no facility to release a radically new design for clinical testing in small groups of tightly controlled and studied patients in specific centres. If a CE mark is granted, the device can be implanted Europe wide.

The United Kingdom is uniquely positioned to evaluate new technology because it has the largest national arthroplasty register in the world, a national patient reported outcome measures project covering hip and knee replacement, and an orthopaedic devices evaluation project (ODEP) review process that assesses the published data (ODEP considers data from all published sources, including industry) and national and 
international arthroplasty data on hip prostheses and bench marks these against accepted standards. These standards are the National Institute for Health and Clinical Excellence guidelines that an implant should have, or be compatible with, $90 \%$ success at 10 years, or if before 10 years, have a failure rate of not more than $1 \%$ per year. What is missing is a process that brings these data together in a timely fashion to identify both good and poor performance as quickly as possible. This would enable successful technology to be introduced quickly and safely but poor technology to be identified earlier and, if necessary, stopped to reduce the risk to patients. It is in no one's interest to implant poorly performing implants.

Collaboration between interested parties delivers results. The UK was the first country to introduce guidance on metal on metal joint replacement after collaboration between the British Orthopaedic Association, the British Hip Society, the Medicines and Healthcare Products Regulatory Agency (MHRA), and the National Joint Registry. ${ }^{8}$

This collaborative approach needs to be extended beyond compliance with basic European Union rules that allow new implants to be introduced. In this endeavour, the British Orthopaedic Association has brought all stakeholders together and recently led a meeting with the MHRA and industry to establish how to improve the process by reviewing premarket testing and clinical trials, as well as by greatly enhancing post-market surveillance. ${ }^{9}$ Better and more effective post-market surveillance is essential; arthroplasty registers have an important role to play in this but may not be enough on their own.
Competing interests: All authors have completed the ICMJE uniform disclosure form at www.icmje.org/coi_disclosure.pdf (available on request from the corresponding author) and declare: no support from any organisation for the submitted work; no financial relationships with any organisations that might have an interest in the submitted work in the previous three years; no other relationships or activities that could appear to have influenced the submitted work.

Provenance and peer review: Commissioned; not externally peer reviewed.

Sedrakyan A, Normand S-LT, Dabic S, Jacobs S, Graves S, Marinac-Dabic D. Comparative assessment of implantable hip devices with different bearing surfaces: systematic appraisal of evidence. BMJ 2011;343:d7434.

2 Anissian HL, Stark A, Gustafson A, Good V, Clarke IC. Metal-on-metal bearing in hip prosthesis generates 100 -fold less wear debris than metal-on-polyethylene. Acta Orthop Scand 1999;70:578-82.

3 Cuckler JM, Moore KD, Lombardi AV Jr, McPherson E, Emerson R. Large versus small femoral heads in metal-on-metal total hip arthroplasty. J Arthroplasty 2004;19(8 suppl 3):41-4.

4 Goodfellow JW, O'Connor JJ, Murray DW. A critique of revision rate as an outcome measure: re-interpretation of knee joint registry data. $J$ Bone Joint Surg Br 2010;92:1628-31.

5 Carrothers AD, Gilbert RE, Jaiswal A, Richardson JB. Birmingham hip resurfacing: the prevalence of failure. J Bone Joint Surg Br 2010;92:1344-50.

6 Curfman GD, Redberg RF. Medical devices-balancing regulation and innovation. N Eng/ $J$ Med 2011;365:975-7.

7 Howie DW, Middleton RG, Costi K. Loosening of matt and polished cemented femoral stems. J Bone Joint Surg Br 1998;80:573-6.

8 Medicines and Healthcare Products Regulatory Agency. Medical device alert MDA/2010/033. All metal-on-metal (MOM) hip replacements, 2010. www.mhra.gov.uk/ home/groups/dts-bs/documents/medicaldevicealert/con079162.pdf.

9 Medicines and Healthcare Products Regulatory Agency. Medical Device Technology Forum Orthopaedic Workshop. Hip implants. Are we ensuring patient safety? 4 Novembe 2011, London, UK.

Cite this as: BMJ 2012;344:d8188

๑ BMJ Publishing Group Ltd 2011 